\title{
The asphalt pavement structure mechanics response under the even
}

\section{speed moving load}

\author{
Jian-hong Gao \\ Architecture and Civil Engineering School,UST Inner Mongolia,Baotou 014010,China \\ gjh76219@163.com
}

\begin{abstract}
KEYWORD: Moving load, Asphalt Pavement Structure, Mechanics response
ABSTRACT: Aiming at the common asphalt pavement structure combination, large general finite element software is used to build the three-dimensional model based on the multi-layer elastic system theory. The pavement structure vertical displacement and stress are analyzed entirely under the even speed moving load. The results show: during the load from the left side to the right side, the node vertical displacement move up and down along with the time extends. Most displacement is down, occasionally up to the road surface. The load affects to its around nodes vertical stress quite little, but the load acted node vertical stress is more than the adding pressure, and the vertical stress will be a slight fluctuation within a certain period of time after the load is removed. All of that illustrate the influence to the pavement structure layer of the dynamic load is different clearly compared with the static load, and the influence results can not be ignored.
\end{abstract}

\section{Introduction}

The vehicle axis load on the road is heavier and the channel transportation characteristic is clearer along with expressway development quickly. So the pavements always appear early part damage: such as push motion, crack, rut etc early damages. One side, the causes of these damages is affected by environmental factors. On the other hand is affected by the traffic load. The load static pressure will affect the service life of the road; the car's dynamics will also cause serious diseases on pavement. At present the city road and highway design in China are all based on elastic layered system under the static load model, and the actual wheel loads are dynamic, the road bearing the vertical vibration and shock \& horizontal effect along with time changing. As the pavement structure itself is sensitive to load time, so the mechanics properties caused from the dynamic load are different greatly from the static model. Using finite element software and the structure dynamics and vibration theory to building the asphalt pavement dynamic load three-dimensional entity mode, the pavement structure mechanics response under the even speed moving load is calculated, and the structure layer stress and displacement under the dynamic load are discussed. So some useful laws can be given and referenced.

\section{Moving load}

The moving load belongs to the dynamics field. Different from the static analysis, dynamic analysis must consider the load change with time and its influence on the damping and inertia. According to structure bearing the load type, dynamic analysis can be roughly divided into the following types: Modal analysis, Spectral analysis, Random vibration analysis and the transient dynamic analysis. The transient dynamic analysis is mainly used for analysis of structure response of load changes with time; ensure that the structure does not appear to damage under impact load. The pavement structure layer mechanical response analysis of moving load is a transient dynamics time course analysis in this paper. 


\section{The finite element model building and interrelated parameters selection}

\section{ANSYS model.}

The paper chooses multy-layer pavement structure and supposes the material is linear \& elastomeric, shown as figure 1 . The building model cell is three-dimensional hexahedron 8 -node and the model $\operatorname{size}(X, Y 、 Z)$ is $3.0 \mathrm{~m} \times 2.0 \mathrm{~m} \times 2.0 \mathrm{~m}$. The boundary: underside $U Y=0$; driving directions is $\mathrm{X}$ direction, and from beginning to end $\mathrm{UX}=0 ; \mathrm{Z}$ direction is the road width and no restriction. The contact condition is entirety continuum. The load is BZZ-100, that is to say the axis heft $100 \mathrm{kN}$, the wheel pressure $0.7 \mathrm{Mpa}$. The wheel load is treated as circular \& average distributing load in engineering design, namely double-round load. Each round diameter is $21.3 \mathrm{~cm}$, and acreage is $356.33 \mathrm{~cm}^{2}$, and the centre distance of double-round is $31.95 \mathrm{~cm}$.In addition, this paper uses international units.

\section{Moving load parameters.}

In this paper, the transient analysis uses FULL method. The design speed $V=20 \mathrm{~km} / \mathrm{h}$. In order to save the computer running time and get enough precision, model grid division is dense close to the pavement structure layer, and is sparse near the road bottom. The scalar parameters are pre defined in order to using the APDL for programming to realize repeated load. Mainly these parameters include the element unit length in the load moving direction, load velocity, the magnitude of load and passing time by each element.

The program will eventually transform the initial load into nodes load, and become a concentrated load no matter its adding form in the finite element method. So this paper program imposed concentrated load directly to the nodes. According to the international system of units the load should be N, standard axle load should be $100000 \mathrm{~N}$. The concentrated load moves from the first node to the

last node with a constant velocity through programming *do and *enddo cycle statement. The load is deleted after the end of each load step, and then it is applied to the next node to solve, in turn forward until the end. Each load step was divided into 5 load step.

The compute model adopts the typical semi rigid pavement structure; specific data are shown in table 1 .

Table 1 pavement structure combination

\begin{tabular}{|c|c|c|c|}
\hline combination & $\begin{array}{c}\text { Modulus and } \\
\text { thickness }\end{array}$ & $\begin{array}{c}\text { Poisson } \\
\text { ratio }\end{array}$ & density \\
\hline $\begin{array}{c}\text { Asphalt } \\
\text { concrete } \\
\text { surface } \\
\text { layer }\end{array}$ & $\begin{array}{c}\mathrm{E} 1=1200 \mathrm{Mpa} \\
\mathrm{h} 1=27 \mathrm{~cm}\end{array}$ & 0.35 & $\begin{array}{c}2400 \\
\mathrm{~kg} / \mathrm{m}^{3}\end{array}$ \\
\hline $\begin{array}{c}\text { Semi-rigid } \\
\text { layer }\end{array}$ & $\begin{array}{c}\mathrm{E} 2=1300 \mathrm{Mpa} \\
\mathrm{h} 2=48 \mathrm{~cm}\end{array}$ & 0.2 & $\begin{array}{c}2400 \\
\mathrm{~kg} / \mathrm{m}^{3}\end{array}$ \\
\hline groundwork & $\begin{array}{c}\mathrm{E} 0=40 \mathrm{Mpa} \\
\mathrm{h} 3>200 \mathrm{~cm}\end{array}$ & 0.4 & $\begin{array}{c}1800 \\
\mathrm{~kg} / \mathrm{m}^{3}\end{array}$ \\
\hline
\end{tabular}




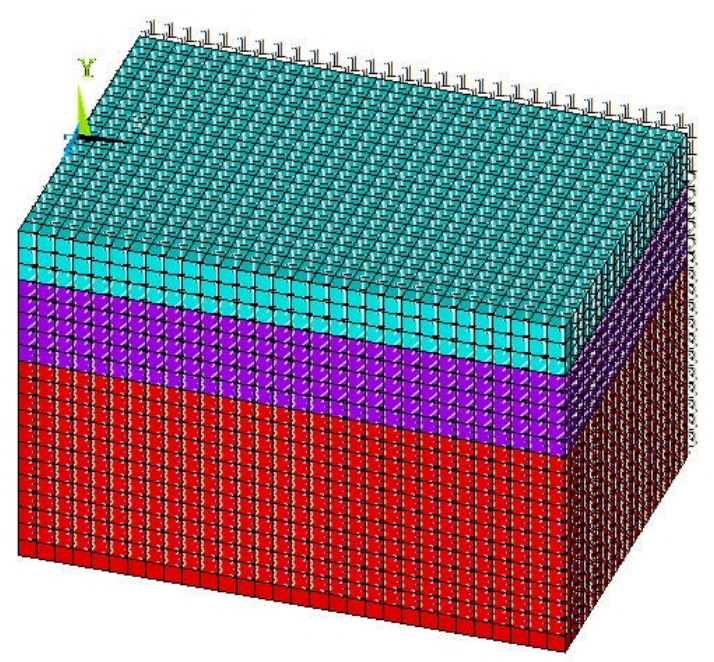

Figure. 1 The finite element model

\section{Pavement structure parameter}

The compute model adopts the typical semi rigid pavement structure; specific data are shown in table 1. The assumptions are as follows:

The pavement each layer materials are continuous \& homogeneous and isotropic and linear elastic.

Each layer of pavement structures in the vertical direction is completely continuous. The inter layer does not appear void phenomenon under the traffic load and the action of gravity. The asphalt surface layer and basic layer are continuous contact conditions.

\section{The asphalt pavement dynamic response finite element analysis under a constant velocity moving load}

The node vertical displacement of load passing change regulations with time.

Figure 2 (a) is the load moving direction and passing node diagram, and 5 representative nodes are chosen in the load moving track. Figure $2(\mathrm{~b}) \sim(\mathrm{d})$ shows the curves of vertical displacement with time of 3 nodes from the graph (a). The node is jumping up and down with load moving indicated from the curves of vertical displacement with time of one node. Most of time, the node vertical displacement is down the road surface, occasionally is over the road surface to bounce up and down, refer to fig.2. The moving load always has effect on surrounding nodes vertical displacement no matter load lying anywhere, but little effect. The load node vertical displacement is maximum and the displacement has different values in different nodes. The maximum vertical displacement is big more and more when the load closes to model both ends ( $\mathrm{X}$ direction), and the maximum vertical displacement is small and uniform more and more when the load closes to model middle, the above are affected mainly from the constraint conditions, and the vertical displacement near the end is distorted a little.

Analyzing on the changes of the 3 curves in Figure 2, the node curves before the model middle position are sloping upward overall when the load moves from left to right. Some displacements are up the road surface, and the farther away from the load point, the more obvious the displacement above road surface. The curve changes smoothly in the model middle position and all points' displacements are below the surface, and no above surface displacements. The node curves after the model middle position are skewed to the bottom-right overall. 


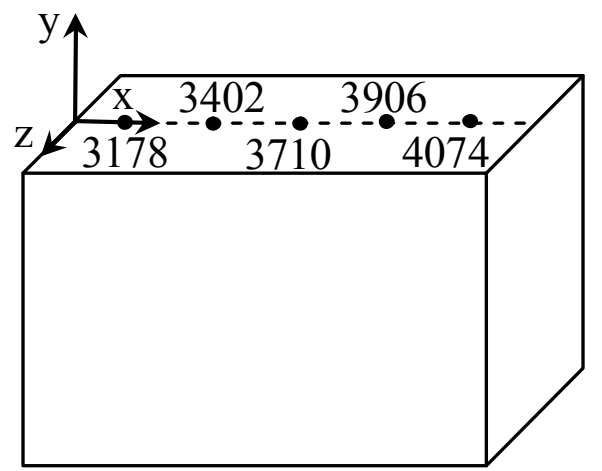

(a) load moving direction and passing nodes

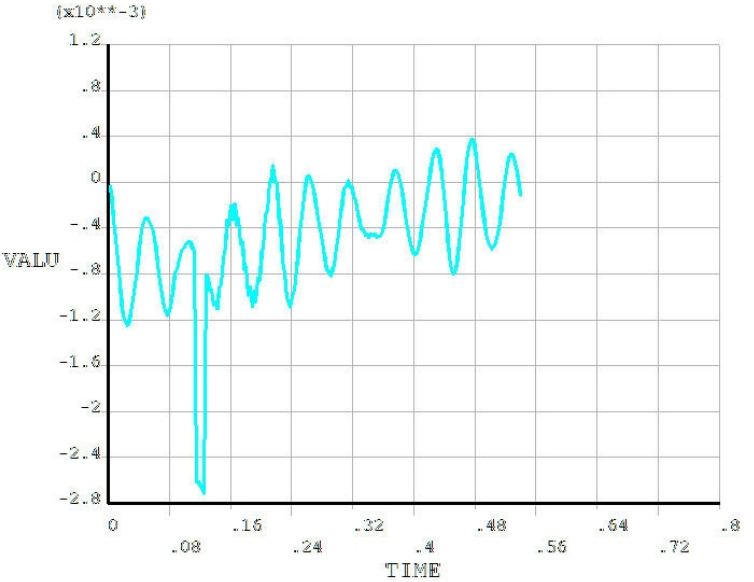

(b) node $3402 \mathrm{UY} \sim$ time curve

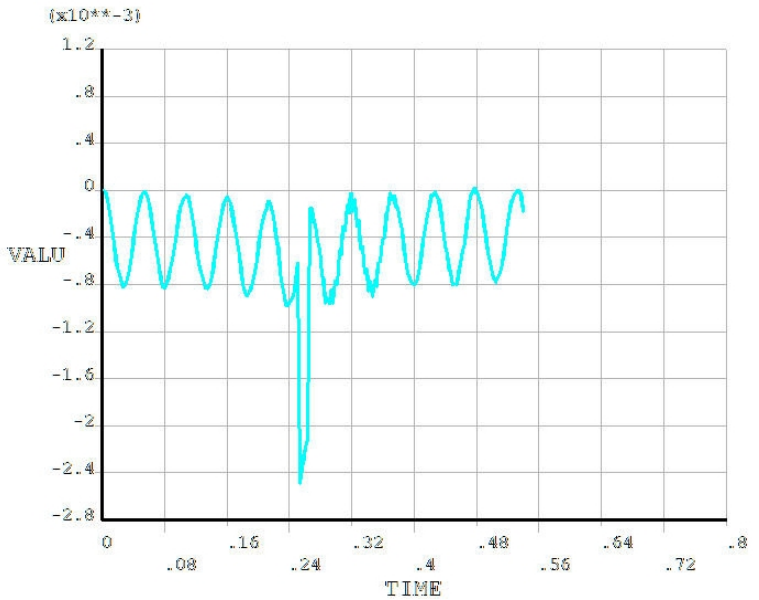

(c) node $3710 \mathrm{UY} \sim$ time curve 


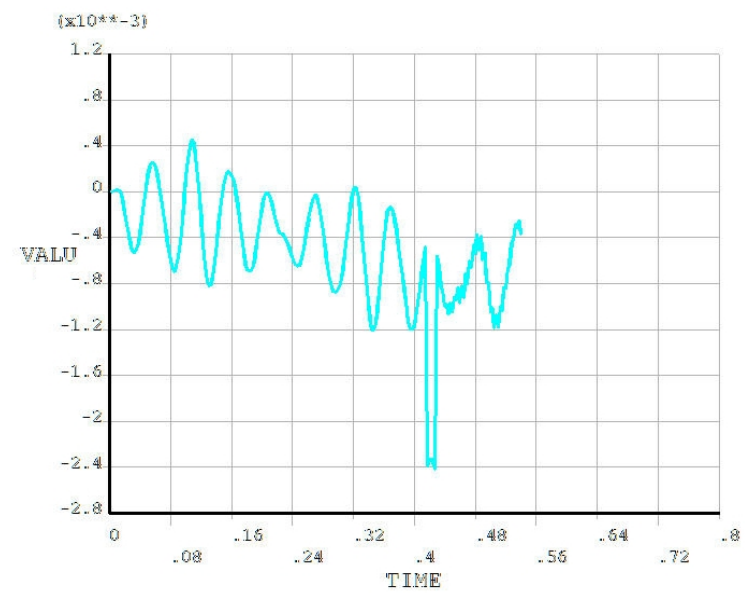

(d) node $3906 \mathrm{UY} \sim$ time curve

Figure 2 some nodes vertical displacement (UY) and time curves

Still some displacements are up the road surface, and the farther away from the load point, the more obvious the displacement above road surface.

\section{The load passing nodes vertical stress and time change laws}

The finite element program used in this article provision: stress in tension is positive, stress in compression is negative. Figure 3 shows those nodes' vertical direction stress and time curves, and those nodes are from Figure 2 (a). The load has little effect to its around nodes vertical direction stress when the load moves from left to right, as shown in Fig. 3. The vertical stress of load acting point is more than the applied load pressure and the node stress still keep a slight fluctuation within a certain period of time after the load leaving. All of that illustrates the dynamic load influence to the pavement layer is different obviously from the static load, and the effect results can not be ignored.

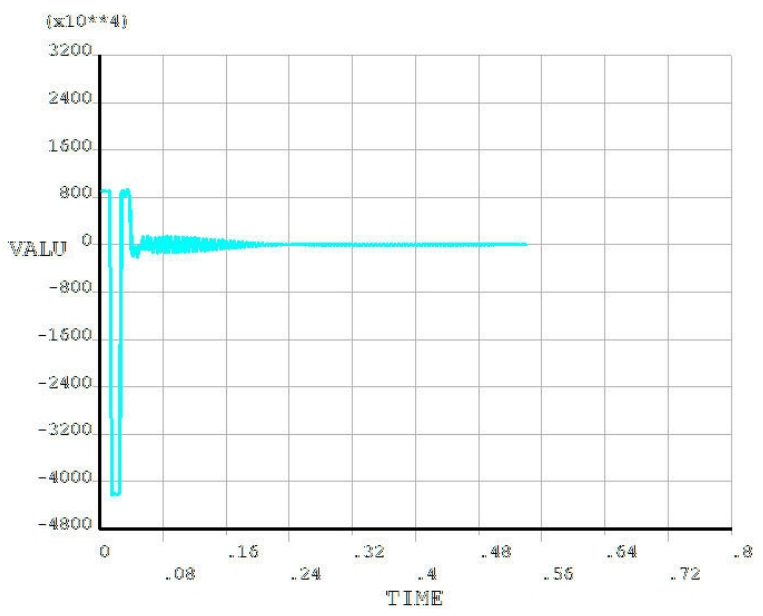

(a) node $3178 \mathrm{SY} \sim$ time curve 


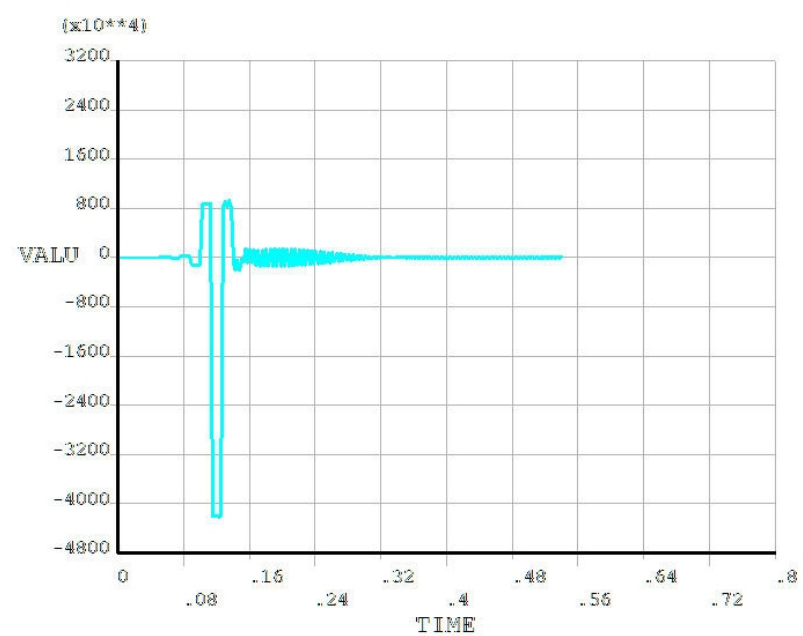

(b) node $3402 \mathrm{SY} \sim$ time curve

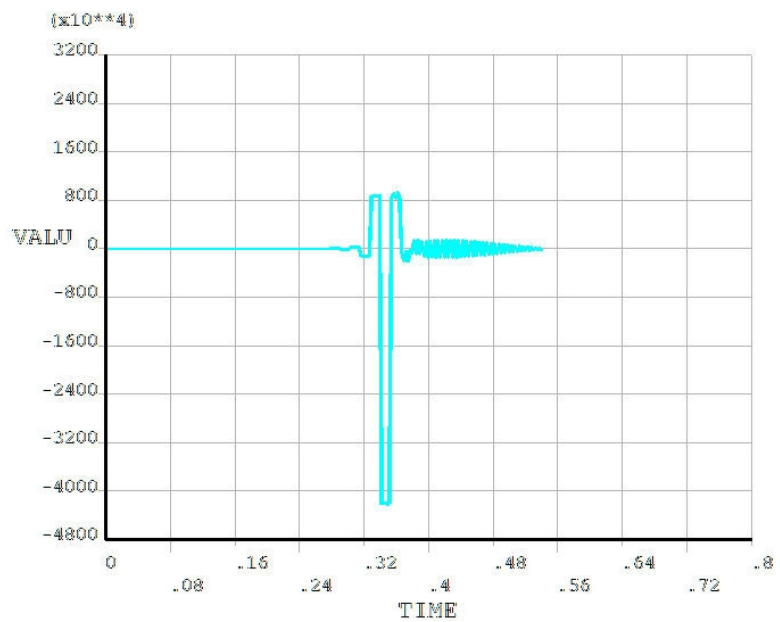

(c) node $3906 \mathrm{SY} \sim$ time curve

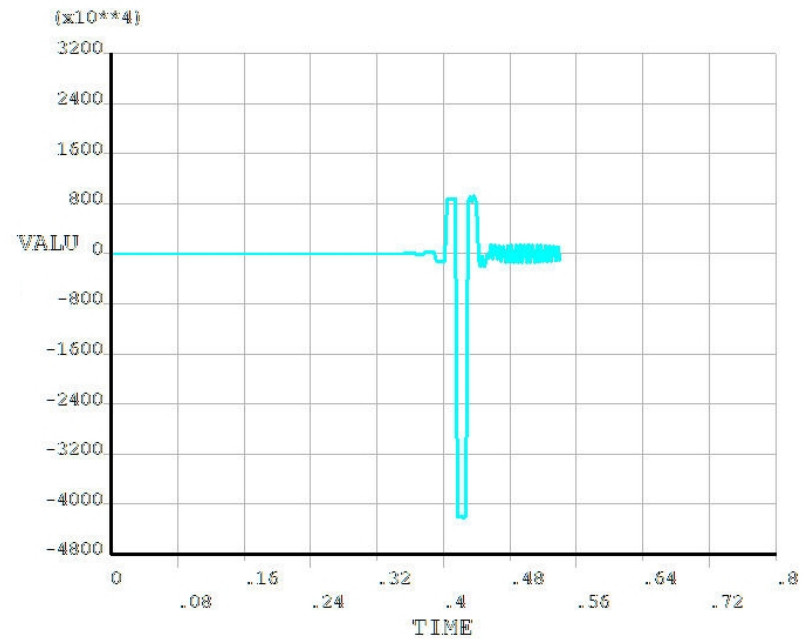

(d) node $4074 \mathrm{SY} \sim$ time curve

Figure. 3 some nodes vertical stress (SY) and time curves

In addition, the load acting point will produce a large compressive stress, and the neighboring points will produce small tensile stress. It is caused of the comprehensive action of load 
characteristics and the material properties of the pavement structure layer, and is fitted to the actual situation and the experiment.

\section{Conclusions}

The node is jumping up and down with load moving to the curves of vertical displacement with time of one node. Most of time, the node vertical displacement is down the road surface, occasionally is over the road surface to bounce up and down. The moving load always has effect on surrounding nodes vertical displacement no matter load lying anywhere, but has little effect. The load node vertical displacement is maximum and the displacement has different values in different nodes.

The load has little effect to its around nodes vertical direction stress when the load moves from left to right. The vertical stress of load acting point is more than the applied load pressure and the node stress still keep a slight fluctuation within a certain period of time after the load leaving. All of that illustrates the dynamic load influence to the pavement layer is different obviously from the static load, and the effect results can not be ignored.

\section{References}

[1] Ben-guo He. ANSYS civil engineering application examples [M]. Beijing: China water resources and hydropower publishing company, 2011.

[2] China calling criterion. Criterion for design of road asphalt concrete pavement. (JTG D50-2006).Beijing: people traffic publishing company, 2006 